\title{
Community pharmacy COPD services: what do researchers and policy makers need to know?
}

This article was published in the following Dove Press journal:

Integrated Pharmacy Research and Practice

7 February 2017

Number of times this article has been viewed

\section{Michael J Twigg \\ David J Wright}

School of Pharmacy, University of East Anglia, Norwich Research Park, Norwich, UK
Correspondence: Michael J Twigg

School of Pharmacy, Norwich Research Park, Earlham Road,

Norwich NR4 7TJ, UK

Tel +44 I6035920I5

Email m.twigg@uea.ac.uk
Abstract: COPD is a leading cause of morbidity and mortality across the world and is responsible for a disproportionate use of health care resources. It is a progressive condition that is largely caused by smoking. Identification of early stage COPD provides an opportunity for interventions, such as smoking cessation, which prevent its progression. Once diagnosed, ongoing support services potentially provide an opportunity to assist the patient in managing their condition and working more closely with the rest of the primary care team. While there are a number of robust studies which have demonstrated the role which pharmacists could undertake to identify and prevent disease progression, adoption of such services is currently limited. As a service that would seem to be appropriate for adoption in all societies where smoking is prevalent, we have performed a review of reported approaches that have been used when setting up and evaluating such services, and therefore aim to inform researchers and policy makers in other countries on how best to proceed. Implementation science has been used to further contextualize the findings of the review in terms of components that are likely to enhance the likelihood of implementation. With reference to screening services, we have made clear recommendations as to the identification of patients, structure and smoking cessation elements of the program. Further work needs to be undertaken by policy makers to determine the approaches that can be used to motivate pharmacists to provide this service. In terms of ongoing support services, there is some evidence to suggest that these would be effective and cost-effective to the health service in which they are implemented. However, the capability, opportunity and motivation of pharmacists to provide these, more complex, services need to be the focus for researchers before implementation by policy makers.

Keywords: COPD, community pharmacy, screening, spirometry, smoking cessation

\section{Introduction}

In 2012, COPD was the fourth largest cause of mortality in the world, ${ }^{1}$ resulting in 3.1 million deaths. This figure is due to rise as a result of the increasing age in the population and prevalence of smoking particularly in low- and middle-income countries. ${ }^{2}$ There is a significant inter-country variation in the prevalence of COPD with estimation ranging from $5 \%$ to $20 \%{ }^{3,4}$ with an overall average of $7.6 \%{ }^{2}$ There is also a stark variation in the outcomes associated with COPD particularly death rates $(4.4 / 100,000$ in Japan versus 130.5/100,000 in People's Republic of China) and disability-adjusted life years (120 in Japan versus 667 in India). ${ }^{5}$

Usually occurring during midlife, COPD is characterized by reduced lung function, that is slowly progressive and not fully reversible. ${ }^{6}$ The element of reversibility is the main feature that distinguishes COPD from asthma. ${ }^{5,7}$ Both the World Health 
Organization and the Global Initiative for Chronic Obstructive Lung Disease (GOLD) state that COPD is both preventable and treatable. ${ }^{1,6}$ Major causes of the condition include tobacco smoke, occupation dust, vapors and fumes and outside air pollutants. ${ }^{6}$ Risk factors include genetic predisposition, increasing age and infection. Repeated insult from foreign and toxic bodies causes long-term irreversible damage to the structure of the lungs, which becomes progressively worse as exposure continues. Therefore, the main treatment for COPD is the removal of the cause.

If left untreated, COPD symptoms will gradually worsen leading to further complications and eventually death. It has been hypothesized that systemic complications can also arise from COPD as a result of an "overspill" of inflammatory mediators from the lungs into the systemic circulation. ${ }^{8}$ This can give rise to additional comorbidities, such as cardiovascular disease, diabetes and chronic infections. ${ }^{9-11}$ Other comorbidities associated with COPD include depression ${ }^{12}$ and muscle wasting. ${ }^{9}$ As a result of both COPD and its complications, the economic burden of the disease to health care systems and society is significant. It is difficult to assess the cost of COPD, however, as the disease worsens these costs increase dramatically. ${ }^{5,13,14}$ This increase in costs incurred can be traced to the increased risk of infection due to reduced ability to deal with external pathogens, causing an increased demand for antibiotics and reduced lung function, which results in increased contact and cost to the health service. Another key aspect of COPD is patients' ability to manage their own condition and take their medicines as prescribed. If patients are not able to do this, then this will also result in further contact with health services as their condition deteriorates. All of these results in a greater number of general practitioner (GP) appointments, greater number of prescribed medicines, increased hospitalizations and decreased quality of life and productivity.

Until recently, pharmacists' main role in patients with COPD centered on prescription supply and counseling on medicines, including inhaler technique. However, with the recent development of more patient facing, clinical and public health roles for pharmacists' new approaches to care being investigated largely center on identifying people who are currently undiagnosed ${ }^{15-17}$ or providing support and education to those with established COPD. ${ }^{18,19}$ The aim of this study is to describe these approaches and determine what researchers and policy makers can learn to inform future intervention design.

\section{Identifying people with undiagnosed COPD}

The role of the pharmacist in identifying people at risk of, or with undiagnosed, long-term conditions, such as diabetes, ${ }^{20-23}$ cardiovascular disease, ${ }^{24-28}$ depression ${ }^{29}$ and coeliac disease, ${ }^{30}$ has long been established. In patient surveys of using community pharmacies to screen patients for various conditions, participants rated services positively and were happy to be screened in the pharmacy environment. ${ }^{31,32}$ However, concerns relating to confidentiality and privacy have been raised. With $90 \%$ of community pharmacies in the UK now having a consultation room, ${ }^{33}$ this is a problem that should now have been overcome. As a result of this work, it has also been suggested that researchers need to do more to understand the extent to which patients listen to the pharmacist's advice and document the resultant actions taken. ${ }^{32}$

With reference to COPD, Castillo et al used 13 community pharmacies in Spain to identify people with the condition who were undiagnosed. ${ }^{16}$ Pharmacists were provided with additional training and targeted people visiting the pharmacy who were over the age of 40 years. They then asked direct questions relating to history of smoking and symptoms indicative of COPD. Depending on the response, the person was then offered the screening service. This involved the administration of the GOLD questionnaire ${ }^{34}$ followed by spirometry if they answered "yes" to more than 3 questions. Pharmacists were then directed to refer patients with an forced expiratory volume in 1 second $\left(\mathrm{FEV}_{1}\right)$ /forced vital capacity $(\mathrm{FVC})$ ratio $<0.7$ to the hospital for further tests. In total, 74\% (188) of targeted patients agreed to participate, of which $100(55.2 \%)$ needed spirometry as a result of their questionnaire answers. Of these 100, $21(21 \%)$ were referred to the hospital as their $\mathrm{FEV}_{1} / \mathrm{FVC}$ ratio was $<0.7$. At hospital referral, all of the findings were confirmed; however, no information relating to the confirmation of diagnosis was provided to the research team.

With demonstrable success in identifying patients with undiagnosed COPD in a small number of pharmacies, Castillo et al then widened this approach to a larger population. ${ }^{15}$ The only changes made to the study design were to increase the number of pharmacies to 100 , refer patients to the primary care physician rather than the hospital and the research team attempted to follow the patient to establish the end diagnosis after the screening process had been completed. This follow-up study established the same trend in results in terms of acceptance of screening process, number of people at high risk from the questionnaire and number identified as needing referral from the spirometry. Although the research team attempted to determine the eventual diagnosis for all referred patients, this was deemed unsuccessful as it relied on physicians completing a questionnaire and returning it to the pharmacy, which did not happen.

In both of these studies, pharmacists have been trained in the use of spirometry in order to provide a more robust 
assessment of lung function before referral to either a hospital or a primary care physician. The use of spirometry by pharmacists has recently been the subject of a review by Cawley and Warning who established from eight studies that pharmacists, with additional training, demonstrated acceptable repeatability of the use of spirometers in a variety of different settings and intervention styles. ${ }^{35}$

A final study to assess the ability of pharmacists to identify patients with undiagnosed COPD was recently published by the coauthors of this study. Wright et al used broadly the same approach as Castillo et al instead of using a different validated screening tool ${ }^{36}$ alongside spirometry, regardless of the results from the questionnaire. ${ }^{17}$ This study also used a more indirect approach of identifying people for the screening program. People were identified in the community either because they were a smoker or they were a known regular purchaser of cough medicines. In total, 238 patients were screened, of which 135 (56.7\%) were identified as at high risk from either the questionnaire or spirometry results. Of this, 88 were current smokers, of which 46 (52.3\%) accepted a smoking cessation service provided by the pharmacy or an external organization, for example, medical practice. In addition to this, 23 patients either engaged in a smoking cessation service in the pharmacy or were referred to another organization despite not being identified as being at high risk of the COPD. A cost-effectiveness analysis was also performed and identified that for every patient screened this would result in a saving of $\sim £ 400$ to the health service.

An integral part of all of these screening programs has been the ability for pharmacists to provide smoking cessation to those people identified with potential COPD. In the case of Wright et al, even patients not at risk of the condition accepted the offer of this additional service, thereby reducing their potential future risk of developing COPD. In a systematic review and meta-analysis published by Brown et al examining the evidence for community pharmacist public health interventions, smoking cessation services were identified as both effective and cost-effective when compared with usual care.$^{37}$ With the link between smoking and the development and progression of COPD clearly established, ${ }^{6}$ this provides evidence that the community pharmacist may have a role in preventing, detecting and halting the progression of the disease with the provision of additional public health services in addition to a screening program.

\section{Supporting people with established COPD}

Much of the research in this field has combined asthma and COPD. A 2014 systematic review and meta-analysis by
Zhong et al identified 14 studies that examined a pharmacist intervention in asthma and COPD. ${ }^{19}$ These focused on management of drug therapy, education (inhaler technique and condition management) and smoking cessation. In most of the interventions, the pharmacist met with the patient more than once during the study period. The evidence producing these results came from well-conducted randomized controlled trials (RCTs) with a duration of 6-12 months, largely in outpatient settings. ${ }^{38-42}$ The review highlighted that a pharmacist intervention does not alter clinical outcomes, such as $\mathrm{FEV}_{1}$ or emergency department visits. However, it did find improvements in quality of life, reductions in routine hospital visits and an increase in medication adherence.

This review also examined papers where the pharmacist had formed part of a collaborative team, usually formed of physicians and nurses. ${ }^{19}$ These interventions were less conclusive about their contribution to the improvement in quality of life..$^{43,44}$ In these studies, the role of the pharmacist was generally confined to providing education on various aspects of medicines, for example, pharmacology or identification of drug-related problems.

More recently, a further review has also been published in this field: this time specifically focusing on the role of the community pharmacist. ${ }^{18}$ Again, the interventions identified focused on key areas of asthma and COPD management and support including ${ }^{45-52}$

1. assessment of current symptoms;

2. assessment and rectification of inhaler technique;

3. identification of medication-related problems;

4. medication adherence;

5. provision of written and oral education materials; 6. smoking cessation.

These studies used a variety of study designs with majority focusing on education for inhaler technique and adherence. Most studies used either cross-sectional design to estimate the problems in asthma and COPD patients and then provide advice with no follow-up or only provided one opportunity for a further discussion. This further opportunity for discussion appeared to center more on the testing of the effectiveness of the intervention rather than follow-up of the patient. Andreevska et al, Tommelein et al and Wright et al focused solely on COPD and used a more sustained intervention with repeated patient discussions over a series of months. A summary of the interventions from both systematic reviews that focus solely on COPD is shown in Table 1 together with the intervention characteristics and main outcomes.

Tommelein et al demonstrated a significant increase in medication adherence and inhalation rate and a reduction 
in hospital admissions when compared with usual care, however, produced no evidence for the effect on symptom management. ${ }^{47}$ Wright et al demonstrated an improvement in adherence and health-related quality of life. ${ }^{45}$ Both Tommelein et al and Wright et al also demonstrated their intervention would be cost-effective to the health system in which it was tested. ${ }^{45,53}$ Similar to the previous study that focused solely on RCTs, the outcomes of this wider review indicate that pharmacists can contribute to improving quality of life, medication adherence (and technique) and reducing medicines wastage, routine hospital visits and routine GP appointments and were, therefore, cost-effective.

\section{Intervention design and implementation}

In all of the screening studies highlighted, pharmacists received extra training to provide the service. This appears central to them having the ability to interpret the results and provide lifestyle advice as part of the intervention. In the identification of suitable patients or customers for this screening service, it is important to have a clear set of criteria. None of the studies highlighted used a population approach to screening instead preferring a more targeted approach by using age, smoking history or the purchase of cough medicines as a proxy for the condition. There is an opportunity for researchers to investigate the number of potential COPD sufferers missed using this targeted approach to determine whether this is an effective method of recruitment.

In the design of the service, it appears appropriate to have a combination of screening questionnaires, for example, COPD assessment test or GOLD, and spirometry in order to identify those with undiagnosed COPD. The most appropriate service design is likely to resemble that used by Castillo et al as this will also avoid unnecessary spirometry testing on those not identified as high risk from a validated screening questionnaire. Using this two-stage process will avoid unnecessary referrals to primary care based on just one measure of lung function.

As part of any service, it is clear that smoking cessation should form a central component. Due to the relationship between smoking and the development of COPD, it is potentially inappropriate to deliver a screening service without having the expertise to deliver (or refer to) a smoking cessation service. This has multiple benefits from reducing the risk of developing the condition to slowing the progression of the disease in those in whom it is already established.

Finally, at present, there is inconsistency in the referral pathway for patients diagnosed as potentially having COPD. These referral pathways should be explicit and integrated into the rest of the primary care team. In the UK, at present, screening services usually rely on patients referring themselves to see their GP. Ideally, the pharmacist should be the person who refers the patient along with the outcome of the screening process. This will, therefore, establish a direct care pathway for those with a potential diagnosis. This direct care pathway would also assist evaluators in establishing the actual diagnosis rate in those patients referred and would provide greater weight to the evidence for pharmacist involvement in the identification of these patients.

It is important to contextualize these findings in the literature on implementation science as this will aid the successful realization of a new approach to services. Implementation science provides researchers and policy makers with a framework for enhancing the design of interventions to ensure maximal uptake in a given setting. One such framework is the COM-B. This describes implementation in terms of a practitioners' capability, opportunity and motivation to act and that all three need to be in place for success. ${ }^{54}$ For screening services, the evidence clearly shows that pharmacists have the capability (once training has been provided) and the opportunity (the number of patients willing to be tested and the methods of identification work well). In terms of motivation, it is not clear from the evidence presented what degree of motivation pharmacists have for screening patients. Methods of establishing this may include payment per identified patient and ensuring pharmacists are made aware of confirmed cases as a result of their efforts, thereby providing a positive feedback loop.

In terms of ongoing support services, the evidence in the context of the COM-B is less clear as this is likely to be a more complex intervention to perform. Key characteristics of the service will likely include multiple consultations over an extended period of time, a focus on education, adherence and inhaler technique and incorporation of greater interprofessional working with the primary care team to enable quicker access to "rescue" medication. However, in terms of the pharmacists' capability, opportunity and motivation to perform this service, further work is required to establish facilitators and barriers to allow successful implementation in the future.

\section{Conclusion}

This review has shown that community pharmacists can identify people with undiagnosed COPD and provide support to their ongoing care and this can be cost-effective to the health service. For researchers and clinicians who are designing, implementing and evaluating these services in practice, there are some key messages that have emerged. Screening services have been described in terms of the central components to aid implementation for policy makers, and 


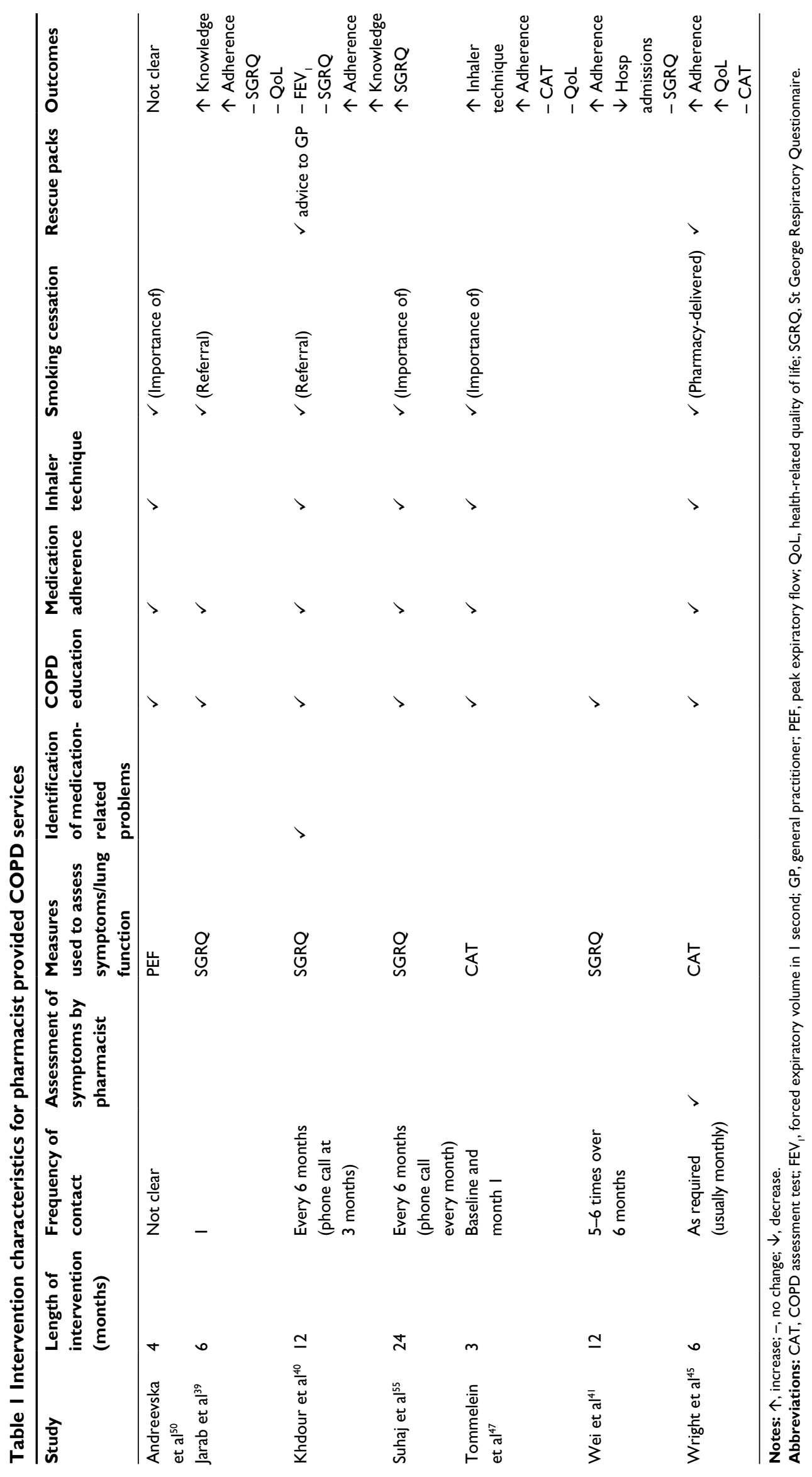


the target for further research has been described to inform the design and testing of ongoing support services.

\section{Disclosure}

DW and MJT have received remuneration from commercial companies for evaluating community pharmacy services. The authors report no other conflicts of interest in this work.

\section{References}

1. WHO. The Top 10 Causes of Death; 2014. Available from: http://www. who.int/mediacentre/factsheets/fs310/en/index 2.html. Accessed July 13, 2016.

2. Halbert R, Natoli J, Gano A, Badamgarav E, Buist AS, Mannino DM. Global burden of COPD: systematic review and meta-analysis. Eur Resp J. 2006;28(3):523-532.

3. Buist AS, McBurnie MA, Vollmer WM, et al. International variation in the prevalence of COPD (the BOLD Study): a population-based prevalence study. Lancet. 2007;370(9589):741-750.

4. Menezes AMB, Perez-Padilla R, Jardim JB, et al. Chronic obstructive pulmonary disease in five Latin American cities (the PLATINO study): a prevalence study. Lancet. 2005;366(9500):1875-1881.

5. Mannino DM, Buist AS. Global burden of COPD: risk factors, prevalence, and future trends. Lancet. 2007;370(9589):765-773.

6. Global Initiative for Chronic Obstructive Lung Disease. Global strategy for the diagnosis, management, and prevention of chronic obstructive pulmonary disease; 2006. Available from: http://www.who.int/respiratory/copd/GOLD_WR_06.pdf. Accessed July 13, 2016.

7. Pauwels RA, Rabe KF. Burden and clinical features of chronic obstructive pulmonary disease (COPD). Lancet. 2004;364(9434):613-620.

8. Sinden NJ, Stockley RA. Systemic inflammation and comorbidity in COPD: a result of 'overspill' of inflammatory mediators from the lungs? Review of the evidence. Thorax. 2010;65(10):930-936.

9. Agusti A, Noguera A, Sauleda J, Sala E, Pons J, Busquets X. Systemic effects of chronic obstructive pulmonary disease. Eur Respir J. 2003;21(2):347-360.

10. Curkendall SM, Lanes S, de Luise C, et al. Chronic obstructive pulmonary disease severity and cardiovascular outcomes. Eur J Epidemiol. 2006;21(11):803-813.

11. Mallia P, Johnston SL. Mechanisms and experimental models of chronic obstructive pulmonary disease exacerbations. Proc Am Thorac Soc. 2005;2(4):361-366.

12. Di Marco F, Verga M, Reggente M, et al. Anxiety and depression in COPD patients: the roles of gender and disease severity. Respir Med. 2006;100(10):1767-1774.

13. Punekar Y, Shukla A, Mullerova H. COPD management costs according to the frequency of COPD exacerbations in UK primary care. Int $J$ Chron Obstruct Pulmon Dis. 2014;9:65-73.

14. Andersson F, Borg S, Jansson SA, et al. The costs of exacerbations in chronic obstructive pulmonary disease (COPD). Respir Med. 2002;96(9):700-708.

15. Castillo D, Burgos F, Guayta R, et al. Airflow obstruction case finding in community-pharmacies: a novel strategy to reduce COPD underdiagnosis. Respir Med. 2015;109(4):475-482.

16. Castillo D, Guayta R, Giner J, et al. COPD case finding by spirometry in high-risk customers of urban community pharmacies: a pilot study. Respir Med. 2009;103(6):839-845.

17. Wright $\mathrm{D}$, Twigg M, Thornley T. Chronic obstructive pulmonary disease case finding by community pharmacists: a potential cost-effective public health intervention. Int J Pharm Pract. 2015;23(1):83-85.

18. Hesso I, Gebara SN, Kayyali R. Impact of community pharmacists in COPD management: inhalation technique and medication adherence. Respir Med. 2016;118:22-30.

19. Zhong H, Ni XJ, Cui M, Liu XY. Evaluation of pharmacist care for patients with chronic obstructive pulmonary disease: a systematic review and meta-analysis. Int J Clin Pharm. 2014;36(6):1230-1240.
20. Twigg MJ, Wright DJ, Thornley T, Haynes L. Community pharmacy type 2 diabetes risk assessment: demographics and risk results. Int J Pharm Pract. 2015;23(1):80-82.

21. Hersberger EK, Botomino A, Mancini M, Bruppacher R. Sequential screening for diabetes - evaluation of a campaign in Swiss community pharmacies. Pharm World Sci. 2006;28(3):171-179.

22. Sookaneknun P, Saramunee K, Rattarom R, et al. Economic analysis of the diabetes and hypertension screening collaboration between community pharmacies and a Thai government primary care unit. Prim Care Diabetes. 2010;4(3):155-164.

23. Krass I, Mitchell B, Clarke P, et al. Pharmacy diabetes care program: analysis of two screening methods for undiagnosed type 2 diabetes in Australian community pharmacy. Diabetes Res Clin Pract. 2007;75(3):339-347.

24. Donyai P, Van den Berg M. Coronary heart disease risk screening: the community pharmacy Healthy Heart Assessment Service. Pharm World Sci. 2009;31(6):643-647.

25. Hourihan F, Krass I, Chen T. Rural community pharmacy: a feasible site for a health promotion and screening service for cardiovascular risk factors. Aust J Rural Health. 2003;11(1):28-35.

26. Mangum SA, Kraenow KR, Narducci WA. Identifying at-risk patients through community pharmacy-based hypertension and stroke prevention screening projects. J Am Pharm Assoc. 2003;43(1):50-55.

27. Horgan JMP, Blenkinsopp A, McManus RJ. Evaluation of a cardiovascular disease opportunistic risk assessment pilot ('Heart MOT' service) in community pharmacies. J Public Health (Oxt). 2010;32(1):110-116.

28. Peterson GM, Fitzmaurice KD, Kruup H, Jackson SL, Rasiah RL. Cardiovascular risk screening program in Australian community pharmacies. Pharm World Sci. 2010;32(3):373-380.

29. Hare SK, Kraenow K. Depression screenings: developing a model for use in a community pharmacy. J Am Pharm Assoc. 2008;48(1): 46-52.

30. Urwin H, Wright D, Twigg M, McGough N. Early recognition of coeliac disease through community pharmacies: a proof of concept study. Int J Clin Pharm. 2016;38(5):1294-1300.

31. Taylor J, Krska J, Mackridge A. A community pharmacy-based cardiovascular screening service: views of service users and the public. Int $J$ Pharm Pract. 2012;20(5):277-284.

32. Ayorinde AA, Porteous T, Sharma P. Screening for major diseases in community pharmacies: a systematic review. Int $J$ Pharm Pract. 2013;21(6):349-361.

33. Local Government Association, Public Health England. The community pharmacy offer for improving the public's health: a briefing for local government and health and wellbeing boards; 2016. Available from: http://www.local.gov.uk/documents/10180/7632544/L16-44+The +community+pharmacy+offer+for+improving+the+public+health /78c98919-2a94-4799-945d-55253c5cb75e. Accessed August 19, 2016.

34. Global Initiative for Chronic Obstructive Lung Disease. Global strategy for the diagnosis, management and prevention of chronic obstructive pulmonary disease. [Updated 2006]. Available from: http://goldcopd. org/. Accessed June 13, 2016.

35. Cawley MJ, Warning WJ. Pharmacists performing quality spirometry testing: an evidence based review. Int J Clin Pharm. 2015;37(5):726-733.

36. Martinez FJ, Raczek AE, Seifer FD, et al. Development and initial validation of a self-scored COPD population screener questionnaire (xCOPD-PS). COPD. 2008;5(2):85-95.

37. Brown TJ, Todd A, O’Malley C, et al. Community pharmacy-delivered interventions for public health priorities: a systematic review of interventions for alcohol reduction, smoking cessation and weight management, including meta-analysis for smoking cessation. BMJ Open. 2016;6(2):e009828.

38. Gourley GA, Portner TS, Gourley DR, et al. Humanistic outcomes in the hypertension and COPD arms of a multicenter outcomes study. $J \mathrm{Am}$ Pharm Assoc. 1998;38(5):586-597.

39. Jarab AS, AlQudah SG, Khdour M, Shamssain M, Mukattash TL. Impact of pharmaceutical care on health outcomes in patients with COPD. Int J Clin Pharm. 2012;34(1):53-62. 
40. Khdour MR, Kidney JC, Smyth BM, McElnay JC. Clinical pharmacyled disease and medicine management programme for patients with COPD. Br J Clin Pharmacol. 2009;68(4):588-598.

41. Wei L, Yang X, Li J, et al. Effect of pharmaceutical care on medication adherence and hospital admission in patients with chronic obstructive pulmonary disease (COPD): arandomized controlled study. J Thorac Dis. 2014;6(6):656-662.

42. Weinberger M, Murray MD, Marrero DG, et al. Effectiveness of pharmacist care for patients with reactive airways disease: a randomized controlled trial. JAMA. 2002;288(13):1594-1602.

43. Gorgas Torner MQ, Pez Vives F, Camos Ramio J, et al. Integrated pharmaceutical care programme in patients with chronic diseases. [Spanish] Programa de atencion farmaceutica integrada en pacientes con enfermedades cronicas. Farmacia Hospitalaria. 2012;36(4):229-239. Spanish.

44. Gallefoss F, Bakke P, Rsgaard PK. Quality of life assessment after patient education in a randomized controlled study on asthma and chronic obstructive pulmonary disease. Am J Resp Crit Care Med. 1999;159(3): 812-817.

45. Wright D, Twigg M, Barton G, Thornley T, Kerr C. An evaluation of a multi-site community pharmacy-based chronic obstructive pulmonary disease support service. Int J Pharm Pract. 2015;23(1):36-43.

46. Ottenbros S, Teichert M, de Groot R, et al. Pharmacist-led intervention study to improve drug therapy in asthma and COPD patients. Int J Clin Pharm. 2014;36(2):336-344.

47. Tommelein E, Van Hees T, Adriaens E, et al. Effectiveness of pharmaceutical care for patients with COPD (PHARMACOP): a randomized controlled trial. Br J Clin Pharmacol. 2014;77(5):756-766.
48. Mehuys E, Boussery K, Adriaens E, et al. COPD management in primary care: an observational, community pharmacy-based study. Ann Pharmacother. 2010;44(2):257-266.

49. Hämmerlein A, Müller U, Schulz M. Pharmacist-led intervention study to improve inhalation technique in asthma and COPD patients. $J$ Eval Clin Pract. 2011;17(1):61-70.

50. Andreevska K, Petkova V, Jordanova S, et al. Effect of education on patients with chronic obstructive pulmonary disease. World J Pharm Pharm Sci. 2013;3(3):01-09.

51. Beauchesne MF, Bercier D, Julien-Baker F, Lalonde L, Boileau R, Blais L . Community pharmacy - based medication assessment program for asthma and chronic obstructive pulmonary disease. Can Pharm J (Ott). 2012;145(2):70-71.

52. Takemura M, Mitsui K, Ido M, et al. Effect of a network system for providing proper inhalation technique by community pharmacists on clinical outcomes in COPD patients. Int J Chron Obstruct Pulmon Dis. 2013;8:239-244

53. van Boven JF, Tommelein E, Boussery $\mathrm{K}$, et al. Improving inhaler adherence in patients with chronic obstructive pulmonary disease: a cost-effectiveness analysis. Respir Res. 2014;15:66.

54. Michie S, van Stralen MM, West R. The behaviour change wheel: a new method for characterising and designing behaviour change interventions. Implement Sci. 2011;6(1):1-12.

55. Suhaj A, Manu MK, Unnikrishnan MK, Vijayanarayana K, Mallikarjuna Rao C. Effectiveness of clinical pharmacist intervention on healthrelated quality of life in chronic obstructive pulmonary disorder patients - a randomized controlled study. J Clin Pharm Ther. 2016;41(1):78-83.
Integrated Pharmacy Research and Practice

\section{Publish your work in this journal}

Integrated Pharmacy Research and Practice is an international, peer-reviewed, open access, online journal, publishing original research, reports, reviews and commentaries on all areas of academic and professional pharmacy practice. This journal aims to represent the academic output of pharmacists and pharmacy practice with particular focus on integrated care. All papers are carefully

\section{Dovepress}

peer reviewed to ensure the highest standards as well as ensuring that we are informing and stimulating pharmaceutical professionals. The manuscript management system is completely online and includes a very quick and fair peer-review system, which is all easy to use. Visit http://www.dovepress.com/ testimonials.php to read real quotes from published authors. 